\title{
Efficient differentiation and function of human macrophages in humanized CSF-1 mice
}

Rathinam, C ; Poueymirou, W T ; Rojas, J ; Murphy, A J ; Valenzuela, D M ; Yancopoulos, G D ; Rongvaux, A ; Eynon, E E ; Manz, M G ; Flavell, R A

\begin{abstract}
Humanized mouse models are useful tools to understand pathophysiology and to develop therapies for human diseases. While significant progress has been made in generating immunocompromised mice with a human hematopoietic system, there are still several shortcomings, one of which is poor human myelopoiesis. Here, we report that human CSF-1 knockin mice show augmented frequencies and functions of human myeloid cells. Insertion of human CSF1 into the corresponding mouse locus of Balb/c Rag2(-/-) c(-/-) mice through VELOCIGENE technology resulted in faithful expression of human CSF-1 in these mice both qualitatively and quantitatively. Intra-hepatic transfer of human fetal liver derived hematopoietic stem and progenitor cells $(\mathrm{CD} 34(+))$ in humanized CSF-1 (CSF1(h/h)) newborn mice resulted in more efficient differentiation and enhanced frequencies of human monocytes/macrophages in the bone marrow, spleens, peripheral blood, lungs, liver and peritoneal cavity. Human monocytes/macrophages obtained from the humanized CSF-1 mice show augmented functional properties including migration, phagocytosis, activation and responses to LPS. Thus, humanized mice engineered to express human cytokines will significantly help to overcome the current technical challenges in the field. In addition, humanized CSF-1 mice will be a valuable experimental model to study human myeloid cell biology.
\end{abstract}

DOI: https://doi.org/10.1182/blood-2010-12-326926

Posted at the Zurich Open Repository and Archive, University of Zurich

ZORA URL: https://doi.org/10.5167/uzh-51310

Journal Article

Published Version

Originally published at:

Rathinam, C; Poueymirou, W T; Rojas, J; Murphy, A J; Valenzuela, D M; Yancopoulos, G D; Rongvaux, A; Eynon, E E; Manz, M G; Flavell, R A (2011). Efficient differentiation and function of human macrophages in humanized CSF-1 mice. Blood, 118(11):3119-3128.

DOI: https://doi.org/10.1182/blood-2010-12-326926 
2011 118: 3119-3128

Prepublished online July 25, 2011;

doi:10.1182/blood-2010-12-326926

\section{Efficient differentiation and function of human macrophages in humanized CSF-1 mice}

Chozhavendan Rathinam, William T. Poueymirou, Jose Rojas, Andrew J. Murphy, David M. Valenzuela, George D. Yancopoulos, Anthony Rongvaux, Elizabeth E. Eynon, Markus G. Manz and Richard A. Flavell

Updated information and services can be found at:

http://bloodjournal.hematologylibrary.org/content/118/11/3119.full.html

Articles on similar topics can be found in the following Blood collections

Phagocytes, Granulocytes, and Myelopoiesis (243 articles)

Information about reproducing this article in parts or in its entirety may be found online at:

http://bloodjournal.hematologylibrary.org/site/misc/rights.xhtml\#repub_requests

Information about ordering reprints may be found online at:

http://bloodjournal.hematologylibrary.org/site/misc/rights.xhtml\#reprints

Information about subscriptions and ASH membership may be found online at: http://bloodjournal.hematologylibrary.org/site/subscriptions/index.xhtml

Blood (print ISSN 0006-4971, online ISSN 1528-0020), is published weekly by the American Society of Hematology, 2021 L St, NW, Suite 900, Washington DC 20036.

Copyright 2011 by The American Society of Hematology; all rights reserved.

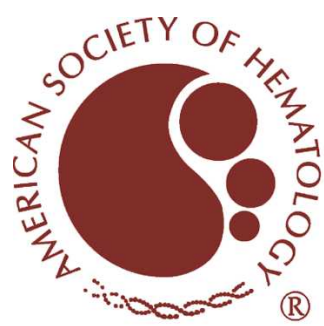




\title{
Efficient differentiation and function of human macrophages in humanized CSF-1 mice
}

\author{
Chozhavendan Rathinam, ${ }^{1}$ William T. Poueymirou, ${ }^{2}$ Jose Rojas, ${ }^{2}$ Andrew J. Murphy, ${ }^{2}$ David M. Valenzuela, ${ }^{2}$ \\ George D. Yancopoulos, ${ }^{2}$ Anthony Rongvaux, ${ }^{1}$ Elizabeth E. Eynon, ${ }^{1,3}$ Markus G. Manz,,${ }^{4,5}$ and Richard A. Flavell ${ }^{1,3}$
}

${ }^{1}$ Department of Immunobiology, Yale University School of Medicine, New Haven, CT; ${ }^{2}$ Regeneron Pharmaceuticals Inc, Tarrytown, NY; ${ }^{3}$ Howard Hughes Medical Institute, Yale University School of Medicine, New Haven, CT; ${ }^{4}$ Division of Hematology, University Hospital Zurich, Zurich, Switzerland; and ${ }^{5}$ nstitute for Research in Biomedicine, Bellinzona, Switzerland

\begin{abstract}
Humanized mouse models are useful tools to understand pathophysiology and to develop therapies for human diseases. While significant progress has been made in generating immunocompromised mice with a human hematopoietic system, there are still several shortcomings, one of which is poor human myelopoiesis. Here, we report that human CSF-1 knockin mice show augmented frequencies and functions of human myeloid cells. Insertion of human CSF1 into the corresponding mouse locus of Balb/c Rag2 ${ }^{-/-} \gamma \mathrm{C}^{-/-}$mice
\end{abstract}

through VELOCIGENE technology resulted in faithful expression of human CSF-1 in these mice both qualitatively and quantitatively. Intra-hepatic transfer of human fetal liver derived hematopoietic stem and progenitor cells $\left(\mathrm{CD}_{3}{ }^{+}\right)$in humanized CSF-1 $\left(\mathrm{CSF}^{\mathrm{h} / \mathrm{h}}\right)$ newborn mice resulted in more efficient differentiation and enhanced frequencies of human monocytes/macrophages in the bone marrow, spleens, peripheral blood, lungs, liver and peritoneal cavity. Human monocytes/ macrophages obtained from the human- ized CSF-1 mice show augmented functional properties including migration, phagocytosis, activation and responses to LPS. Thus, humanized mice engineered to express human cytokines will significantly help to overcome the current technical challenges in the field. In addition, humanized CSF-1 mice will be a valuable experimental model to study human myeloid cell biology. (Blood. 2011; 118(11):3119-3128)

\section{Introduction}

The development of animal models to study human diseases has significantly advanced our understanding of the underlying mechanisms of several diseases, including cancer. To date, animal models, particularly in the laboratory mouse, have proven to be excellent candidates for the evaluation of the efficiency and efficacy of drugs and therapy options. While the utilization of these surrogate models to study human biology and diseases can be largely justified, because of ethical and technical constrains on the conduct of experimental therapies in humans, much study has highlighted the potential limitations of extrapolating data from mice to humans. ${ }^{1}$ It is increasingly evident that there are several differences between the physiology of humans and mice and so, therapies that have been proven successful in mice may not work well in humans.

To overcome these issues, there has been a long-standing interest in developing a "humanized mouse" model and intensive work by several groups has successfully demonstrated the feasibility of studying human biology and diseases in mice. Since, a functional and effective immune system in the recipient mouse will result in the elimination of the transplanted tissues/cells of human origin, use of genetic mutants that lack cells of the adaptive immune system such as T, B, and NK cells has significantly contributed to the success of the "humanized mouse" model. Accordingly, the most effective candidates of humanized mouse models include the NOD-SCID and the Balb/c strains that lack genes including recombination activating genes (RAG), common $\gamma$ chain $(\gamma \mathrm{C})$, beta2 microglobin (B2M), and Perforin 1 (Prf1). ${ }^{2}$ Several studies over the past few decades have demonstrated the feasibility of transplanting several types of human tissues, including peripheral blood leukocytes, fetal liver cells, fetal bone, fetal thymus, fetal lymph nodes, vascularized skin, artery segments, and either mobilized or cord blood hematopoietic stem cells (HSCs), into the humanized mice. ${ }^{3}$ This approach has been believed to provide better model systems becausethe data obtained from human cells in these mice might reflect the physiology of the human system.

A major avenue of investigation in the field is to generate mice with a complete hematopoietic system and a functional immune system of the human origin. Interestingly, there has been much progress in generating human T cells, B cells, NK cells, and DCs from HSCs in humanized mice. ${ }^{2-9}$ In addition to the individual hematopoietic compartment, injection of human HSCs in these mice resulted in the reconstitution of lymphoid organs such as thymus and spleen..$^{2-9}$ Nevertheless, the frequencies of myeloid cells, particularly granulocytes, macrophages, erythrocytes and megakaryocytes, are very low a result that is probably because of inefficient myelopoiesis from human HSCs in these mice. ${ }^{2,3}$ In view of the fact that the cells of myeloid origin; erythrocytes, megakaryocytes macrophages and granulocytes play vital functions, such as oxygen transport, blood coagulation and development of adaptive immune system, generating humanized mice with efficient human myelopoiesis is of paramount importance.
Submitted December 23, 2010; accepted June 28, 2011. Prepublished online as Blood First Edition paper, July 25, 2011; DOI 10.1182/blood-2010-12-326926.
The publication costs of this article were defrayed in part by page charge payment. Therefore, and solely to indicate this fact, this article is hereby marked "advertisement" in accordance with 18 USC section 1734.

(C) 2011 by The American Society of Hematology 
Colony stimulating factor-1 (CSF-1) or macrophage colony stimulating factor (M-CSF) is one of the early cytokines that was discovered to promote hematopoiesis. In the hematopoietic system, CSF-1 is believed to act specifically on myeloid progenitors, starting from the common myeloid progenitor (CMP) stage, and to favor the differentiation of CMPs into the monocyte/macrophage lineage. ${ }^{10}$ In addition, CSF-1 is necessary for the survival, adhesion and motility of macrophages. ${ }^{11-13}$ CSF-1 signals through the CSF-1 receptor (Fms; CD115) and ligation of its receptor by CSF-1 results in tyrosine phosphorylation of Fms and subsequent phosphorylation of several host cell proteins. ${ }^{11,13-15}$

Here, we hypothesized that the defective human myeloid differentiation in the humanized mice might be because of the lack of specific signals that promote myeloid differentiation. To validate this, we engineered a new generation of humanized mice to secrete human CSF-1 at physiologic levels from the appropriate tissues. Analysis of these humanized CSF-1 mice revealed normal expression, both qualitatively and quantitatively, of human CSF-1. Analysis of humanized CSF-1 mice engrafted with human CD34 ${ }^{+}$ cells indicated augmented frequencies of human monocytes/ macrophages in various tissues compared with the control mice. Furthermore, human monocytes/macrophages obtained from these mice exhibited enhanced functional properties over the macrophages that were obtained from control mice.

\section{Methods}

\section{Human CSF1 knockin strategy}

A targeting construct for replacing the mouse with the human CSF1 gene (Velocigene Allele Identification Number 5093) in a single targeting step was constructed using VELOCIGENE technology as described previously. ${ }^{16}$ Mouse and human CSF1 DNA were obtained from bacterial artificial chromosome (BAC) RPCI-23, clone 373B18 and from BAC RPCI-11, clone 101M23, respectively. In brief, a linearized targeting construct generated by gap repair cloning containing mouse $C S F 1$ upstream and downstream homology arms flanking a $17.5 \mathrm{~kb}$ human CSF1 sequences extending from exon 2 to 633 nt downstream of noncoding exon 9 , and a floxed drug selection cassette was electroporated into $R A G 2^{+/-} \gamma_{c}{ }^{-/-}$ mouse embryonic stem (ES) cells, which was made from a commercially available V17 ES cell line (BALB/c $\times 129$ F1). Mouse ES cells carrying a heterozygous deletion of the Csfl gene were identified by Loss-of-Allele screening ${ }^{17}$ (with 2 TaqMan qPCR assays that recognized sequences in intron 2 (TUF primer, 5'-CCAGGAATGTCCACTATGGATTC-3'; TUP probe, $5^{\prime}$ ACTGCTCCTTGACCCTGCT

CTGACTCA-3'; TUR primer, 5'-TGGGCTGACTTCCCAAAGG-3') and in the $3^{\prime}$ flanking sequence (TDF primer, 5'-TTAGGTGCTAGTAGGCTGGAAAGTG-3'; TDP probe, 5'-TGCAATCGCAGCTTCTCTCCTTACTAGGCT-3'; TDR primer, 5' -AATAGGAAGAACGAACAGGTCTAATACC- $3^{\prime}$ ) of the mouse Csf1 gene. Simultaneous replacement of the mouse gene with the human $C S F 1$ gene was confirmed by Gain-of-Allele TaqMan assays that detected one copy of a sequence in intron 2 of CSF1 (forward primer, 5'-GCTGCTTGCCTGGGTTAGTG-3'; probe, 5'-TGCCCAGGAACATCAACCACTGATTCTG-3'; reverse primer, 5'-GAGGGACAGCAGACCTCAGAAG- $3^{\prime}$ ) and one copy of the neomycin resistance $\left(n e o^{\mathrm{r}}\right.$ ) cassette (forward primer, 5'-GGTGGAGAGGCTATTCGGC-3'; probe, 5'TGGGCACAACAGACAATCGGCTG-3'; reverse primer, 5'GAACACGGCGGCATCAG-3'; see supplemental Figure 1, available on the Blood Web site; see the Supplemental Materials link at the top of the online article). The qPCR assay that recognizes the $C S F 1$ sequence does not amplify DNA from the mouse genome. The same assays were used to confirm the genotypes of mice derived from the targeted ES cells. Cre-mediated excision of the drug selection cassette was confirmed with the $n e o^{\mathrm{r}}$ TaqMan assay. All primer-probe sets were supplied by Biosearch Technologies (http://www.biosearchtech.com). Probes were labeled with 6-carboxy-fluorecein (FAM) on their $5^{\prime}$ ends and BHQ-1 on their $3^{\prime}$ ends. Correctly targeted ES cells were further electroporated with a transient Cre-expressing vector to remove the drug selection cassette. Targeted ES cell clones without drug cassette were introduced into an 8-cell stage mouse embryo by the VELOCIMOUSE method. ${ }^{18}$ VELOCIMICE (F0 mice fully derived from the donor ES cell) bearing the humanized CSF1 gene (VG 5093) were identified by genotyping for loss of mouse allele and gain of human allele using a modification of allele assay. ${ }^{16}$

\section{Mice}

$\mathrm{Balb} / \mathrm{c}-\mathrm{Rag} 2^{-/-} \gamma \mathrm{c}^{-/-} \mathrm{CSF}^{\mathrm{m} / \mathrm{m}}, \mathrm{Balb} / \mathrm{c}-\mathrm{Rag}^{-/-} \gamma \mathrm{c}^{-/-} \mathrm{CSF} 1^{\mathrm{h} / m}$ and Balb/ c-Rag2 $2^{-/-} \gamma c^{-/-} C S F 1^{h / h}$ mice were kept under specific pathogen-free conditions in the animal care facility at the Yale University. All mouse experiments were approved by the Institutional Animal Care and Use Committee of the Yale University.

\section{$\mathrm{CD}^{+}{ }^{+}$cell isolation and transplantation}

Human fetal liver samples were obtained from the human fetal liver tissue repository at the Albert Einstein College of Medicine, Bronx, NY and from Advanced Biosciences Resources Inc, Alameda, CA. All experiments involving human tissues were performed under the approval of the Yale Human Investigations Committee.

For isolating human $\mathrm{CD}^{+} 4^{+}$cells, fetal liver samples were rinsed once with PBS and cut into small pieces, treated with collagenase D $(100 \mathrm{ng} / \mathrm{mL})$ at $37^{\circ} \mathrm{C}$ for 45 minutes. Single cell suspensions were prepared and the mononuclear cells were isolated using density gradient centrifugation (Lymphocyte separation medium, MP biomedicals LLC). CD34 ${ }^{+}$cells were immuno-magnetically isolated with anti-human CD34 microbeads by MACS technique according to manufacturer's instructions (Miltenyi Biotech).

For transplantation, newborn mice (within day 1 of birth) were sublethally irradiated with 2 separate doses $(2 \times 150 \mathrm{cGy})$ in a 4 hour interval and $1-2 \times 10^{5}$ purified human $\mathrm{CD}^{2} 4^{+}$cells in $20 \mathrm{uL}$ of PBS were injected into the liver using a 22-gauge needle (Hamilton Company).

\section{Mesenchymal stroma cell isolation and culture}

Long bones of mice were isolated and the BM cells were flushed out. Bones were cut into pieces and digested with a cocktail of collagenase D and $\mathrm{P}$ $(25 \mathrm{ng} / \mathrm{mL})$ for 45 minutes at $37^{\circ} \mathrm{C}$. Suspension cells were isolated and plated in the presence of mesenchymal stroma cell (MSC) culture medium (StemCell Technologies). After 2 weeks of culture, adherent cells were harvested, stained with cocktail of antibodies and $\mathrm{CD} 45^{-} \mathrm{Sca} 1^{+} \mathrm{CD} 90^{+}$ cells were sorted by Moflo high speed cell sorter (Beckman Coulter Inc). These cells were further cultured in the presence of MSC culture medium for 7 days.

\section{Antibodies and flow cytometry}

Single-cell suspensions were analyzed by flow cytometry using FACS Calibur or LSRII and CellQuest software Version 7.5.4, FACS Diva software Version 6.0 (all BD Biosciences) or FlowJo Version 6.3.2 software (TreeStar Inc), respectively. Cell sorting of defined subpopulations was performed using FACS Aria cell sorter (BD Biosciences). The following anti-human antibodies were used in: CD11b, CD14, CD33, CD34, CD38, CD40, CD45, CD80, CD86, CD90, and HLA-DR (BD Biosciences).

The following anti-mouse antibodies were used: CD11b, CD40, CD45, CD80, CD86, F4/80, Gr1, H2K ${ }^{\mathrm{d}}$, and IA ${ }^{\mathrm{d}}$ (BD Biosciences).

\section{Cell culture}

For mouse macrophage differentiation, BM cells were plated in 6 well plates in the presence of DMEM with 10\% FCS, 2mM L-Glutamine, 1\% Penicillin-Streptomycin and $1 \mathrm{mM}$ nonessential amino acids. Cells were treated with either recombinant murine CSF-1 $(10 \mathrm{ng} / \mathrm{mL})$ or recombinant human CSF-1 (10 ng/mL) for 7 days. Cell culture supernatant was removed every third day and culture was replaced with fresh medium and cytokines.

For human macrophage studies, such as activation, phagocytosis and migration, $2 \times 10^{5} \mathrm{CD} 45^{+} \mathrm{CD} 14^{+} \mathrm{CD} 33^{+}$cells of the spleens were 
sorted and cultured in vitro in the DMEM with $15 \%$ human $\mathrm{AB}$ serum, 2mM L-Glutamine, $1 \%$ Penicillin-Streptomycin and $1 \mathrm{mM}$ nonessential amino acids.

\section{Activation, phagocytosis, and migration assays}

For LPS stimulation in vivo, mice were injected intraperitoneally with LPS ( $100 \mathrm{ng} / \mathrm{g}$ body weight). For LPS stimulation in vitro, LPS $(10 \mathrm{ng} / \mathrm{mL})$ was added to the cells and cultured for either 1 or 2 days as mentioned in "Cell culture." For poly I:C stimulation in vitro, cells were cultured in the presence of poly I:C $(10 \mu \mathrm{g} / \mathrm{mL})$ for either 6 or 12 hours.

Phagocytosis assay was performed using the commercially available Vybrant phagocytosis assay kit (Invitrogen) according to the manufacturer's instructions.

Migration assays were performed using a commercially available QCM chemotaxis cell migration assays kit (Millipore) according to the manufacturer's instructions.

\section{RNA extraction and real-time PCR}

Total RNA was isolated using commercially available kit systems (RNeasy Mini kit; QIAGEN). cDNA was synthesised using oligo dT primer and expand reverse transcriptase (Roche). The PCR reaction was performed in duplicates using 7500 real-time PCR systems and power SYBR Green PCR master mix (Applied Biosystems) according to the manufacturer's instructions using the following gene specific primer pairs: Human CSF1 (sense: 5'-TACTGTAGCCACATGATTGGGA-3' and antisense: 5'-CCTGTGTCAGTCAAAGGAAC-3'), Mouse csfl (sense: $5^{\prime}$-CGACATGGCTGGGCTCCC-3' and antisense: $5^{\prime}$-CGCATGGTCTCATCTATTAT-3'), Human IFNa (sense:5'-GTACTGCAGAATCTCTCCTTTCTCCTG-3' and antisense: $5^{\prime}$-GTGTCTAGATCTGACAACCTCCCAGGCACA-3'), Human IFNb (sense:5'-TTGTGCTTCTCCACTACAGC-3' and antisense: 5'-CTGTAAGTCTGTTAATGAAG-3'), Mouse hprt primers (sense: 5'-AAGGACCTCTCGAAGTGTTGGATA and antisense: 5'CATTTAAAAGGAACTGTTGACAACG-3') and Human HPRT primers (sense: 5'-CTTCCTCCTCCTGAGGAGTC-3' and antisense: 5'-CCTGACCAAGGAAAGCAAAG-3').

\section{ELISA}

For cytokine quantification studies, either blood serum or cell culture supernatants were collected and subjected to ELISA using commercially available human CSF-1 (Ray Biotech Inc), human IL-6, and human TNF $\alpha$ ELISA kits (Ray Biotech Inc) according to the manufacturer's instructions.

\section{Histology}

Solid organs were fixed in $4 \%$ PFA. Fixed organs were embedded in paraffin (Blue RiBbon; Surgipath Medical Industries). Blocks were sectioned and the $5-\mu \mathrm{m}$ sections were stained with $\mathrm{H} \& \mathrm{E}$ stain, followed by placement of coverslips by routine methods. Sections were maintained without any medium. Digital light microscopic images were recorded, at room temperature, with a Zeiss Axio Imager.A1 microscope (with $2 \times$ and $10 \times$ objective lenses), AxioCam MRc5 camera, and AxioVision 4.7.1 imaging software (Carl Zeiss Microimaging LLC).

\section{Statistical analysis}

Data are presented as mean \pm SEM. Statistical significance was assessed using a 2 -sided Student $t$ test. $P$ values $<.05$ were considered to be significant.

\section{Results}

\section{Generation of humanized CSF-1 mice}

The Balb/c strain with Rag2 $2^{-/-} \gamma c^{-/-}$deficiency serves as successful model system for the study of the human immune system in mice. ${ }^{8}$ To validate whether physiologic expression of human CSF-1 in a mouse results in improved differentiation of human macro- phages in the humanized mice, we engineered the Balb/c Rag2 $2^{-/}$ $\gamma c^{-1-}$ mice to express human CSF-1. To circumvent supraphysiologic expression of human CSF-1 in these mice, we adopted the strategy to replace the mouse csfl gene with the human counterpart. A construct (supplemental Figure 1) for replacing, in a single targeting step, the mouse csfl open reading frame with the human CSF1 coding region (Velocigene Allele Identification Number 5093), was constructed using the VELOCIGENE technology as described previously. ${ }^{16}$ Of note, the promoter and other regulatory elements (such as $5^{\prime} \mathrm{UTR}$ ) of the mouse were preserved in this vector. The linearized targeting vector was electroporated into the Balb/c $\times 129$ Rag $2^{+/-} \gamma c^{-/-}$. embryonic stem cells. Correctly targeted ES cells were further electroporated with a transient Cre-expressing vector to remove the drug selection cassette. Targeted ES cell clones without drug cassette were introduced into an 8-cell stage mouse embryo by the VELOCIMOUSE method. ${ }^{18}$ VELOCIMICE (F0 mice fully derived from the donor ES cell) bearing the humanized CSF1 gene (VG 5093) were identified by genotyping for the loss of the mouse allele and gain of the human allele using a modification of allele assay. ${ }^{16}$ Through sequential intercrossing of progenies, Balb/c Rag $2^{-/-} \gamma c^{-/-}$mice chimeric mice and germ line transmitted mice with mouse and human CSF-1 (CSF $1^{\mathrm{h} / \mathrm{m}}$; heterozygous knockin) and human CSF-1 only (CSF $1^{h / h}$; homozygous knockin) were generated.

\section{Characterization of the humanized CSF-1 mice}

First, we evaluated the expression of human CSF-1 in the humanized CSF-1 mice. Organs from either $C S F 1^{m / m}$ or $C S F 1^{h / h}$ mice were harvested and analyzed for murine and human CSF1 mRNA expression using primers that are species specific. As shown in Figure 1A and B, CSF-1 is expressed in the majority of the analyzed organs including BM, spleen, blood, liver, brain, lung, testis, and kidney. However, thymus and skin did not show detectable expression of CSF-1. Of note, the expression pattern of mouse and human CSF-1 was comparable between $C S F 1^{\mathrm{m} / \mathrm{m}}$ and $C S F 1^{h / h}$ mice, respectively. Next, we quantified the expression levels of mouse and human CSF-1 in $C S F 1^{\mathrm{m} / \mathrm{m}}, C S F 1^{\mathrm{h} / \mathrm{m}}$ and $C S F 1^{h / h}$ mice. BM mesenchymal stromal cells (MSCs) were isolated and the expression levels of CSF-1 mRNA were quantified using realtime-PCR (Figure 1C) and CSF-1 protein (secreted) was quantified using ELISA (Figure 1D). As expected, $C S F 1^{\mathrm{m} / \mathrm{m}}$ mice expressed only mouse csf-1, $C S F 1^{h / m}$ mice expressed both mouse and human CSF-1 and $C S F 1^{h / h}$ mice expressed only human CSF-1. In addition, the expression level of human CSF-1 was comparable with mouse csf-1. In line with these data, analysis of CSF-1 in serum revealed comparable expression levels of CSF-1 protein in $\mathrm{m} / \mathrm{m}, \mathrm{h} / \mathrm{m}$, and $\mathrm{h} / \mathrm{h}$ mice (Figure 1E). Interestingly, hemizygocity does not lead to decreased gene and protein expression levels, indicating that gene-dosage levels seem not to be limiting for this cytokine.

Earlier studies have documented that mice with defective CSF-1 signaling (Csflop/op and $C s f 1 r^{-/-}$) exhibit tooth eruption failure and bone defects. ${ }^{19-22}$ To investigate whether replacing mouse Csf-1 with human CSF-1 results in deleterious effects, especially on the bone and hematopoiesis, $C S F 1^{h / h}$ mice were analyzed at various ages. However, $C S F 1^{h / h}$ mice revealed normal teeth and bone properties (data not shown). Further, unlike the Csf1 ${ }^{\text {op/op }}$ and Csf1r ${ }^{-1-}$ mice, the total cell content of the BM (Figure 2A), frequencies of myeloid cells in the BM, spleen (SP), and peripheral blood (PB; Figure $2 \mathrm{~B}$ ) and the frequencies of macrophages in the $\mathrm{BM}$ and $\mathrm{SP}$ (Figure $2 \mathrm{C}$ ) were comparable among the $C S F 1^{m / m}, C S F 1^{h / m}$, and $C S F 1^{h / h}$ mice, indicating that human CSF-1 

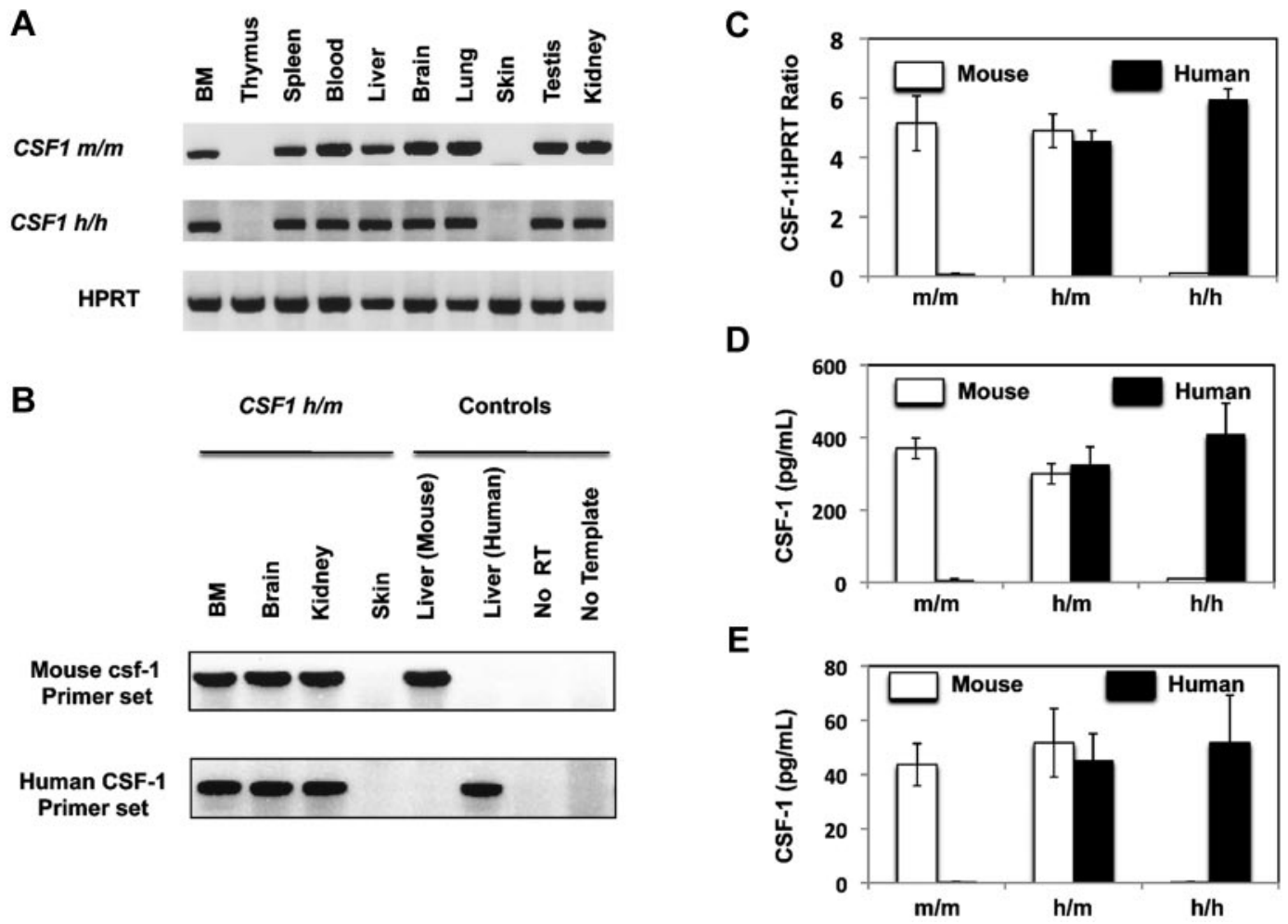

Figure 1. Expression of human CSF-1 in the humanized CSF-1 mice. (A) Indicated organs from CSF $1 \mathrm{~m} / \mathrm{m}$ and $C S F 1^{\text {h/h }}$ were isolated, RNA was extracted- and reverse transcription (RT)-PCR analysis was performed either using mouse CSF-1 (top) or human CSF-1 (middle) specific primers. HPRT levels (bottom) was used as controls for the input cDNA. Data are representative of 2 independent experiments. (B) Indicated organs from CSF $1^{h / m}$ were isolated, RNA was extracted and RT-PCR analysis was performed either using mouse CSF-1 (top) or human CSF-1 (bottom) specific primers. RNA extracted either from mouse liver or human fetal liver served as positive controls for mouse and human primer pairs, respectively, no RT, and no template PCR reactions served as negative controls. Data are representative of 2 independent experiments. (C) Bone Associated Stromal Cells from $\mathrm{CSF}^{\mathrm{m} / \mathrm{m}}, \mathrm{CSF}^{\mathrm{h} / \mathrm{m}}$, and $\mathrm{CSF} 1^{\mathrm{h} / \mathrm{h}}$ mice were isolated and cultured in vitro for 10 days. Cells were lysed, RNA was extracted, and real-time PCR analysis was performed using either mouse CSF-1 (white) or human CSF-1 (black) specific primers. Shown are the mean values of duplicate samples. Error bars indicate \pm SEM. Input cDNA quantity was normalized according to HPRT (hypoxanthine guanine phosphoribosyl transferase) expression levels. Data are representative of 2 independent experiments. (D) Bone Associated Stromal Cells from CSF ${ }^{\mathrm{m} / \mathrm{m}}, \mathrm{CSF} 1^{\mathrm{h} / \mathrm{m}}$, and CSF $1^{\mathrm{h} / \mathrm{h}}$ mice were isolated and cultured in vitro for 10 days. Cell culture supernatants were collected and the secreted levels of mouse (white) and human (black) CSF-1 were quantified using species specific CSF-1 ELISA kits. Shown are the mean values of triplicate samples. Error bars indicate \pm SEM. Data are representative of 2 independent experiments. (E) $C S F 1^{\mathrm{m} / \mathrm{m}}, C S F 1^{\mathrm{h} / \mathrm{m}}$, and $C S F 1^{\mathrm{h} / \mathrm{h}} \mathrm{mice}$ were bled and the serum levels of human and mouse CSF-1 were quantified through ELISA. Shown are the mean values of triplicate samples. Error bars indicate \pm SEM.

shows functional cross-reactivity to mouse cells. In line with this observation, the cellular frequencies within the HSC compartment (including long-term HSC; CD $150^{+} \mathrm{CD} 48^{-} \mathrm{LSK}$, short-term HSCs; CD150 ${ }^{+} \mathrm{CD} 48^{+}$LSK and multipotent progenitors; $\left.\mathrm{CD} 150^{-} \mathrm{CD} 48^{+} \mathrm{LSK}\right)$ and myeloid progenitor compartment (including common myeloid progenitors; Lineage ${ }^{-} \mathrm{c}-$ $\mathrm{Kit}^{+} \mathrm{Sca}{ }^{-}{ }^{-\mathrm{CD}} 34^{+} \mathrm{CD} 16 / 32^{-}$, granulocyte monocyte progenitors; Lineage $^{-} \mathrm{c}-\mathrm{Kit}^{+} \mathrm{Sca}{ }^{-} \mathrm{CD} 34^{+} \mathrm{CD} 16 / 32^{+}$and megakaryocyte erythrocyte progenitors; Lineage ${ }^{-} \mathrm{c}-\mathrm{Kit}^{+} \mathrm{Sca} 1^{-} \mathrm{CD} 34^{-} \mathrm{CD} 16 /$ $32^{-}$) were comparable among the $C S F 1^{\mathrm{m} / \mathrm{m}}, C S F 1^{\mathrm{h} / \mathrm{m}}$, and $C S F 1^{h / h}$ mice (supplemental Figure 2).

A possible explanation for the normal hematopoiesis and bone development in the $C S F 1^{h / h}$ mice is likely that human CSF-1 is cross reactive with mouse cells. Indeed, previous studies documented that human CSF-1 is active in mouse target cells, whereas mouse CSF-1 is not cross active on human cells. ${ }^{23}$ To confirm this, total BM cells from $C S F 1^{m / m}$ were isolated and cultured in the presence of either recombinant murine CSF-1 or recombinant human CSF-1. Whereas BM cells cultured in the absence of cytokine failed to survive, cells cultured in the presence of either human or mouse CSF-1 showed comparable levels of in vitro differentiation (Figure 2D). Analysis of these in vitro differentiated macrophages for the expression of costimulatory molecules and MHC indicated comparable levels of these molecules in the presence of either human or mouse CSF-1 (Figure 2E).

\section{Differentiation of human monocytes/macrophages in humanized CSF-1 mice}

To evaluate the impact of CSF-1 humanization, sublethally irradiated newborn $\mathrm{Rag}^{-/-} \gamma \mathrm{c}^{-/-} \mathrm{CSFl}^{\mathrm{m} / \mathrm{m}}, \mathrm{Rag}^{-/-} \gamma^{-/-} \mathrm{CSF} \mathrm{I}^{\mathrm{h} / \mathrm{m}}$, and $\mathrm{Rag}^{-/-} \gamma \mathrm{c}^{-/-} \mathrm{CSF}^{\mathrm{h} / \mathrm{h}}$ mice were transplanted intrahepatically $(\mathrm{IH})$ with $\sim 2 \times 10^{5}$ purified human fetal liver CD34 ${ }^{+}$ cells. Recipients were bled at 8 weeks after transplantation to confirm the cells of donor origin. 12 weeks after transplantation, recipients were killed and their BM, SP, and PB were harvested. Analysis of donor-derived hematopoiesis, based on human CD45 expression, revealed augmentation of human cell number in the BM, spleen, and blood of humanized CSF-1 $(h / m$ and $h / h)$ mice over $C S F 1^{m / m}$ mice (supplemental Figure 3). As expected the relative and absolute frequencies of $\mathrm{CD} 14^{+} \mathrm{CD} 33^{+}$monocyte/macrophage lineage cells were increased in the BM, SP, and $\mathrm{PB}$ of both $C S F 1^{\mathrm{h} / \mathrm{m}}$ and $C S F 1^{h / h}$ mice compared with $C S F 1^{m / m}$ mice (Figure 3A-C). Although $\mathrm{CSF}^{\mathrm{h} / m}$ mice exhibited increased frequencies of $\mathrm{CD} 14^{+} \mathrm{CD} 33^{+}$cells, the maximum frequencies of $\mathrm{CD} 14^{+} \mathrm{CD} 33^{+}$cells were found in the $\mathrm{CSF}^{h / h}$ mice. Interestingly, in addition to this increase, the frequencies of $\mathrm{CD}_{14}{ }^{-} \mathrm{CD} 33^{+}$cells were also increased in the BM, SP, and PB of $C S F 1^{h / m}$ and $C S F 1^{h / h}$ mice (Figure $3 \mathrm{~A}$ ). Nevertheless, the frequencies of human erythro-mekaryocyte lineage and lymphoid lineage cells remained comparable among $C S F 1^{m / m}, C S F 1^{h / m}$, and $C S F 1^{h / h}$ mice (supplemental Figure 4). 
A

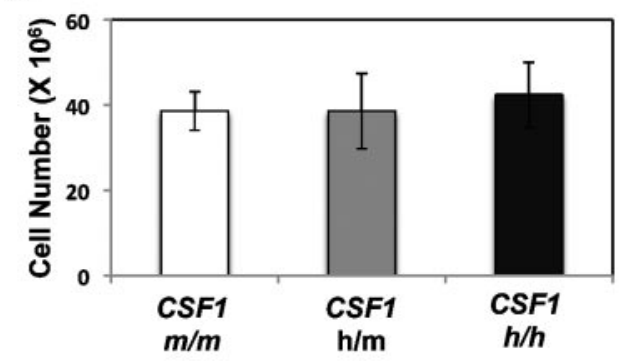

B

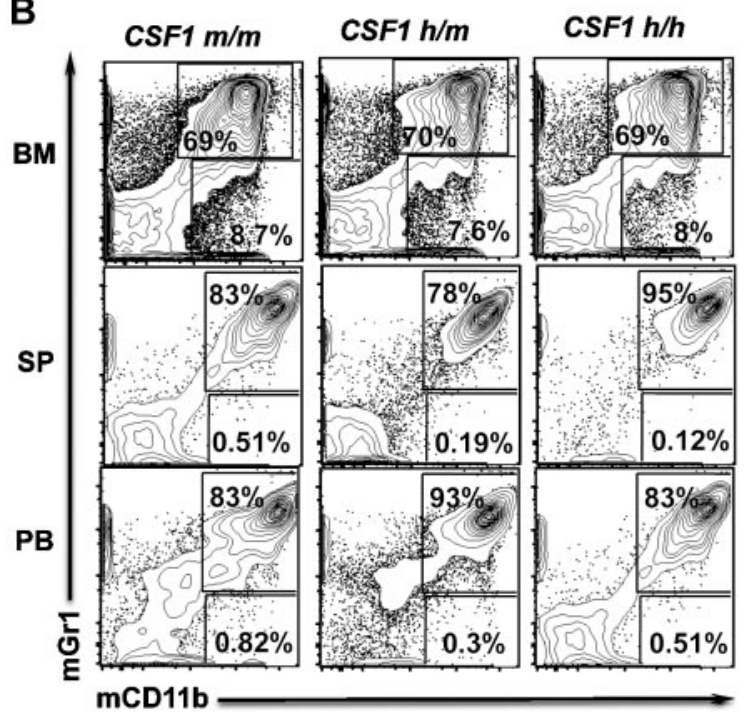

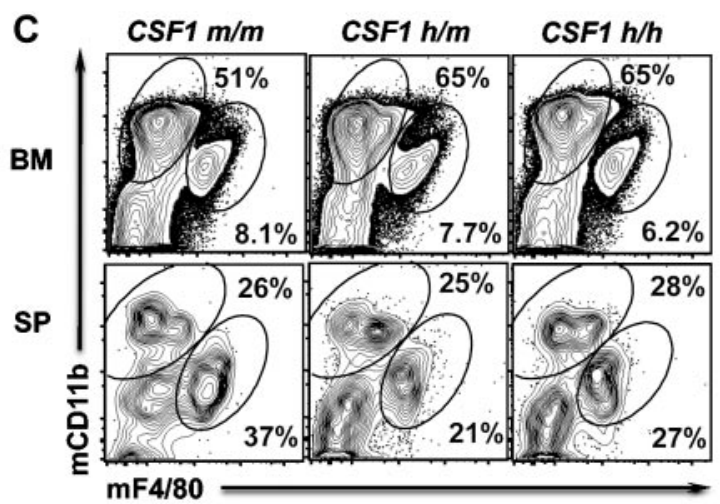

D

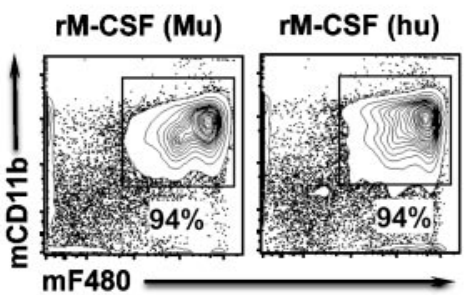

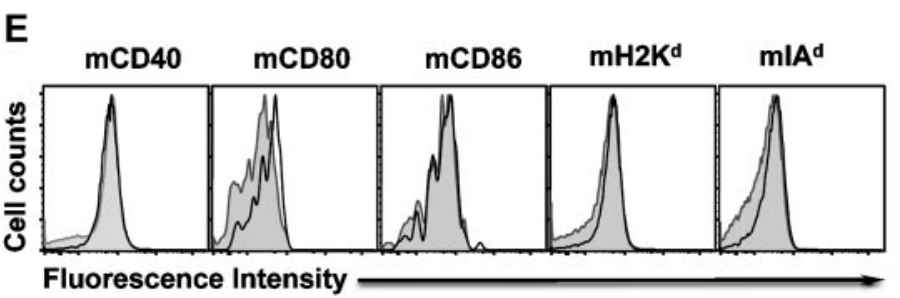

Figure 2. Myeloid differentiation in the humanized CSF-1 mice and cross-reactivity of human CSF-1. (A) Absolute numbers of BM cells of $C S F 1^{m / m}$, CSF $1^{h / m}$, and $C S F 1^{h / h}$ mice, as average per animal (2 tibia and fibula), were determined. Each group contains $\mathrm{n}=5$ mice, age 4 weeks. Error bars indicate $\pm S E M$. Data are representative of 3 independent experiments. (B) Single-cell suspension of BM (top), spleen (middle), and peripheral blood (PB) from CSF1 ${ }^{m / m}, C S F 1^{h / m}$, and $C S F 1^{h / h}$ mice were prepared, stained with Gr1 and CD11b antibodies, and analyzed by flow cytometry. (C) Single-cell suspension of BM (top) and spleen (middle) from CSF1 $\mathrm{m} / \mathrm{m}, C S F 1^{h / m}$, and $C S F 1^{h / h}$ mice were prepared, stained with F4/80 and CD11b antibodies, and analyzed by flow cytometry. (D) BM cells were isolated and cultured in the presence of either recombinant mouse CSF-1 (left) or human CSF-1 (right) for 7 days. Cells were stained with F4/80 and CD11b antibodies and analyzed by flow cytometry. (E) BM cells were isolated and cultured in the presence of either recombinant mouse CSF-1 (filled) or human CSF-1 (open) for 7 days. Cells were stained with indicated surface markers and analyzed by flow cytometry.

To analyze whether human CSF-1 knockin mice support sustained human myelopoiesis, recipients were analyzed at 12 , 16 , and 20 weeks after transplantation. While human $\mathrm{CD} 14^{+} \mathrm{CD} 33^{+}$ monocyte/macrophage lineage cells were slightly reduced at 16 weeks and highly reduced after 20 weeks of transplantation in the $C S F 1^{\mathrm{m} / \mathrm{m}}$ mice, significant proportions of human $\mathrm{CD} 14^{+} \mathrm{CD} 33^{+}$cells were observed in both $C S F 1^{h / m}$ and $C S F 1^{h / h}$ mice at even 16 and 20 weeks. The maximum frequencies of human $\mathrm{CD} 14^{+} \mathrm{CD} 33^{+}$cells were seen in the $C S F 1^{h / h}$ mice (Figure 4A-B).

Next, we assessed whether the humanized CSF-1 mice support efficient differentiation of human tissue macrophages. To this end, $C S F 1^{m / m}, C S F 1^{h / m}$, and $C S F 1^{h / h}$ mice were perfused with PBS and their organs including liver, lungs and skin were harvested. Cells of the peritoneum were obtained by flushing the peritoneal cavity with PBS. Single cell suspensions were prepared and the frequencies of human $\mathrm{CD} 14^{+} \mathrm{CD} 33^{+}$cells were calculated. As expected, the frequencies of human $\mathrm{CD} 14^{+} \mathrm{CD} 33^{+}$cells were significantly increased in the liver, lungs and peritoneum of both $C S F 1^{h / m}$ and $C S F 1^{h / h}$ mice. However, analysis of skin explants revealed comparable frequencies of human $\mathrm{CD} 14^{+} \mathrm{CD} 33^{+}$cells between $C S F 1^{\mathrm{m} / \mathrm{m}}$ and $C S F 1^{\mathrm{h} / \mathrm{m}}$ mice, although a significant increase of these cells was observed in the skin explants of $C S F 1^{h / h}$ mice (Figure 5). Of note, expression of human CSF-1 in mice did not substantially affect the murine microenvironment of organs including spleen, liver and lungs as indicated by similar organ architecture (supplemental
Figure 5). Taken together these data demonstrate that expression of human CSF-1 in mice improves myeloid/macrophage lineage differentiation of human hematopoietic stem and progenitors cells.

\section{Functions of human monocytes/macrophages in the humanized CSF-1 mice}

To investigate whether the human $\mathrm{CD} 14^{+} \mathrm{CD} 33^{+}$monocytes/ macrophages in the humanized CSF-1 mice functioned normally, both in vivo and in vitro functional studies were performed. Sublethally irradiated $C S F 1^{m / m}$ and $C S F 1^{h / m}$ newborn mice were injected with human fetal liver CD34+ cells and 12 weeks after transplantation, donor derived hematopoiesis was assessed and the recipient mice were injected with either LPS or PBS. Two days after LPS injection, recipients were analyzed for the frequencies of human $\mathrm{CD}_{14}{ }^{+} \mathrm{CD} 33^{+}$cells in the spleen. While LPS injection induced only a modest increase of human monocyte/macrophage lineage cells in the $C S F 1^{\mathrm{m} / \mathrm{m}}$ mice, compared with the PBS injected groups, LPS injected $C S F 1^{h / m}$ mice showed a several fold increase of human $\mathrm{CD}_{14}{ }^{+} \mathrm{CD} 33^{+}$cells in the spleen (Figure 6A). Next we determined the ability of these cells to produce pro-inflammatory cytokines in response to LPS stimulation in vivo. $C S F 1^{\mathrm{m} / \mathrm{m}}$ and $C S F 1^{h / m}$ mice engrafted with human CD34+ cells were injected with LPS and 6 hours after injection, mice were bled and the serum levels of human and mouse IL- 6 and TNF $\alpha$ were determined by 
A

12 weeks after transplantation with human CD34+ cells

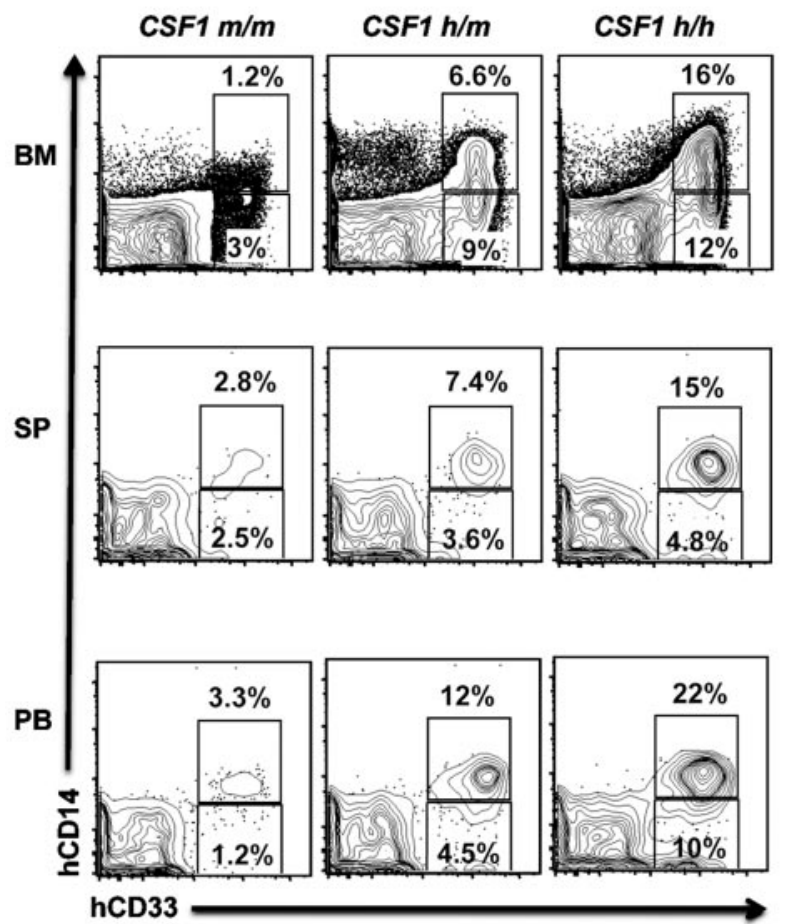

B
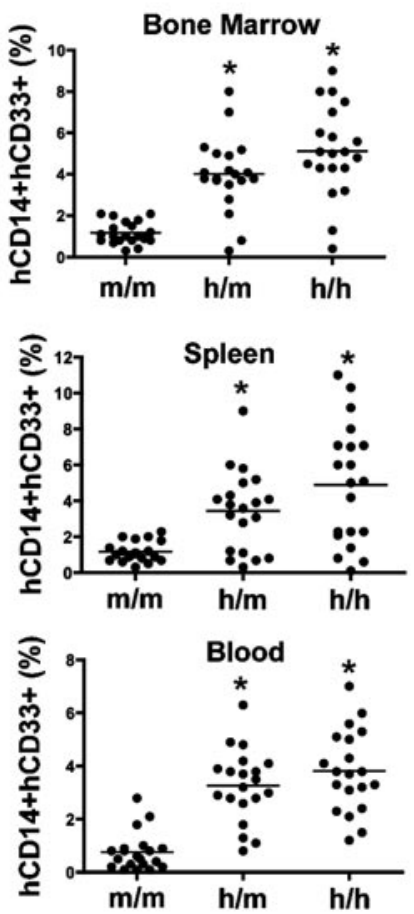

C
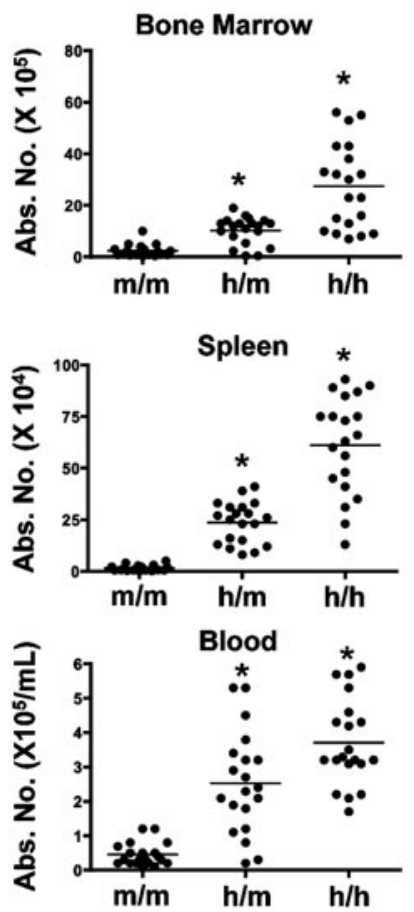

Figure 3. Human myeloid differentiation in the humanized CSF-1 mice. (A) Single-cell suspension of BM (top), spleen (middle), and peripheral blood (PB) from human $\mathrm{CD}^{2} 4^{+}$cells engrafted $\mathrm{CSF} 1^{\mathrm{m} / \mathrm{m}}, \mathrm{CSF} 1^{\mathrm{h} / \mathrm{m}}$, and $\mathrm{CSF} 1^{\mathrm{h} / \mathrm{h}}$ mice were prepared, stained with CD45, CD14, and CD33 human antibodies, and analyzed by flow cytometry. Cells that are human $\mathrm{CD}_{4} 5^{+}$were pregated and discriminated based on CD14 and CD33 expression. (B-C) Percentages (B) and absolute numbers (C) of human CD45 $\mathrm{CD}_{14}{ }^{+} \mathrm{CD} 33^{+}$cells of BM (top), spleen (middle), and peripheral blood (PB) were calculated. Absolute numbers of BM cells were determined as average per animal ( 2 tibia and fibula) and of peripheral blood were determined per milliliter volume of blood. Each group contains $\mathrm{n}=20$ mice. Each symbol represents an individual mouse; horizontal bars indicate the mean values. Data are representative of 5 independent experiments.

ELISA. Consistent with the increased frequencies of monocytes/ macrophages in the humanized CSF-1 mice, elevated levels of human IL-6 and human-TNF $\alpha$, but not mouse IL-6 and mouse
$\mathrm{TNF} \alpha$, were detected in the $C S F 1^{h / m}$ mice. Although the basal levels of these cytokines were higher in the $C S F 1^{\mathrm{h} / \mathrm{m}}$ mice, LPS stimulation resulted in augmented levels of human IL-6 and human
A

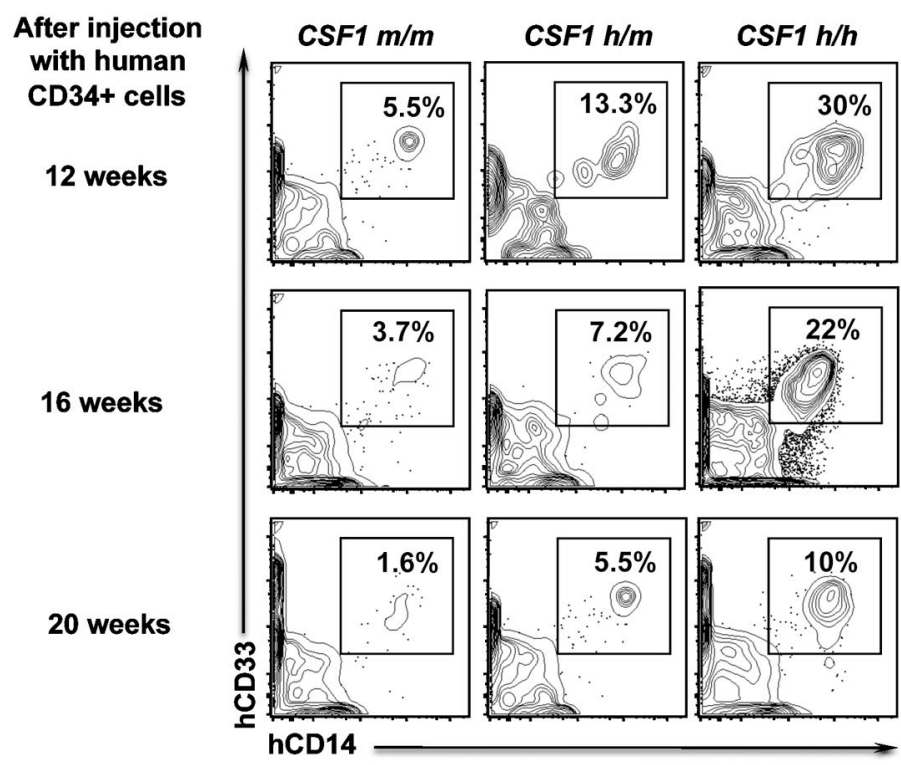

B

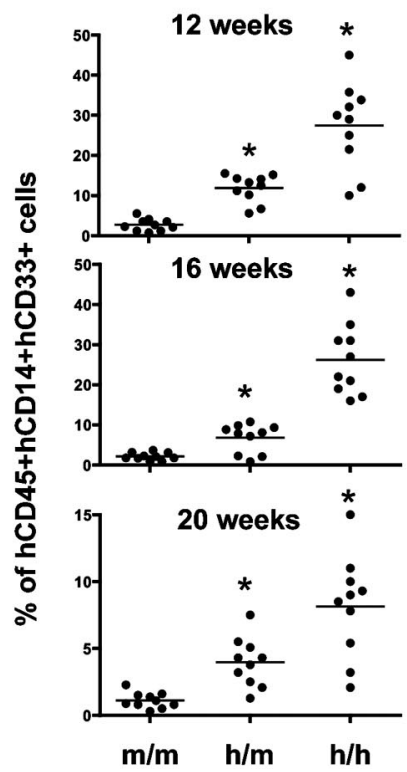

Figure 4. Sustained human myeloid differentiation in the humanized CSF-1 mice. (A) Human CD34+ cells engrafted CSF $1^{m / m}, C S F 1^{h / m}$, and $C S F 1^{h / h}$ mice were bled after 12,16 , and 20 weeks of transplantation. Cells were stained with CD45, CD14, and CD33 human antibodies, and analyzed by flow cytometry. Cells that are human CD45 ${ }^{+}$were pregated and discriminated based on CD14 and CD33 expression. (B) Relative frequencies of human CD45 ${ }^{+}$CD14 ${ }^{+}$CD33 ${ }^{+}$cells were plotted. Each group contains $n=10$ mice. Each symbol represents an individual mouse; horizontal bars indicate the mean values. Data are representative of 3 independent experiments. 
Figure 5. Frequencies of tissue-derived human monocytes/macrophages in the humanized CSF-1 mice. $C S F 1^{m / m}, C S F 1^{h / m}$, and $C S F 1^{h / h}$ mice were engrafted with human $\mathrm{CD} 34^{+}$cells, and 12 weeks after transplantation, mice were killed perfused with PBS. Liver (A), lungs $(B)$, and skin (C) were harvested and single-cell suspensions were prepared. Peritoneal cavity cells (D) were collected by aspirating with PBS. Cells were stained with human CD45, CD14, and CD33 antibodies, and analyzed by flow cytometry. Each symbol represents an individual mouse; horizontal bars indicate the mean values. Data are representative of 3 independent experiments.

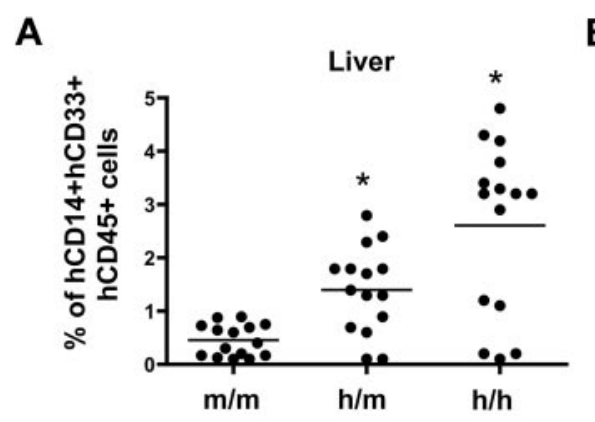

C

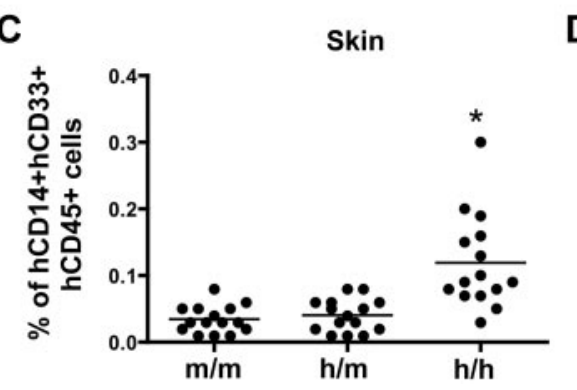

B

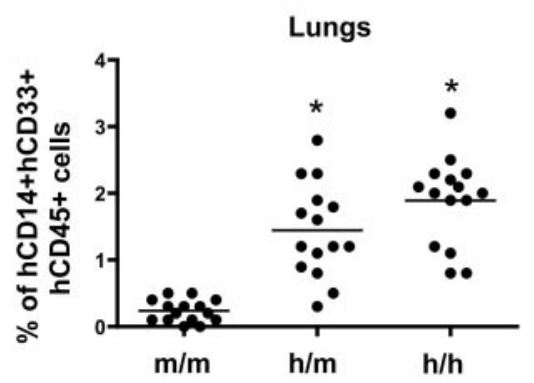

D

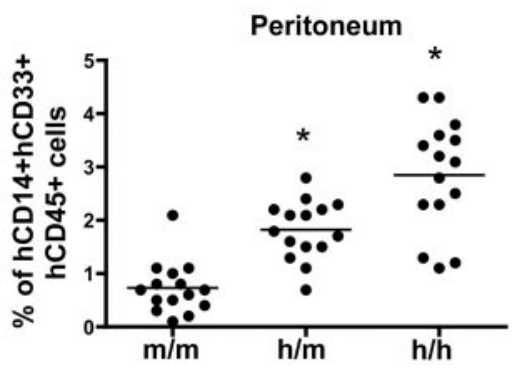

$\mathrm{TNF} \alpha$ in the serum (Figure 6B-C), most likely, because of increased numbers of human monocytes/macrophages in $C S F 1^{h / m}$ mice over $C S F 1^{\mathrm{m} / \mathrm{m}}$ mice. We also analyzed the capacity of monocytes/macrophages, obtained from humanized CSF-1 mice, to secrete pro-inflammatory cytokines in vitro. Human $\mathrm{CD} 14^{+} \mathrm{CD} 33^{+}$cells were isolated from the spleens of either $C S F 1^{m / m}$ or $C S F 1^{h / h}$ mice, after 12 weeks of reconstitution with human $\mathrm{CD}_{3} 4^{+}$cells, and stimulated with LPS in vitro for either 24 or 48 hours. The levels of human IL- 6 and TNF $\alpha$ cytokines in the cell culture supernatants were assessed by ELISA. $\mathrm{CD} 14^{+} \mathrm{CD} 33^{+}$cells purified from $C S F 1^{h / h}$ mice secreted augmented levels of these cytokines in response to LPS, similar as human fetal liver cell derived cells (Figure 7A-B). Similarly, human $\mathrm{CD} 14^{+} \mathrm{CD}_{3}{ }^{+}$cells isolated from the humanized CSF-1 mice expressed augmented levels of IFN- $\alpha$ and IFN- $\beta$ mRNA in response to poly I:C stimulation (Figure 7C). Finally, we analyzed the phagocytic, migratory and activation properties of human monocytes/macrophages obtained from the humanized CSF-1 mice. Human $\mathrm{CD}_{14}{ }^{+} \mathrm{CD} 33^{+}$cells purified from human $\mathrm{CD} 34^{+}$ reconstituted, $C S F 1^{h / h}$ mice exhibited increased phagocytosis (Figure 7D) and displayed enhanced chemotaxis in response to the chemokine Mip3 $\beta$ (Figure 7E). In addition, human monocytes/ macrophages obtained from the $C S F 1^{h / h}$ mice displayed enhanced activation properties as assessed based on up-regulation of costimulatory molecules including CD40, CD80 and CD86, and HLA-DR in response to LPS stimulation in vitro (Figure 7F). Overall, besides increased quantity, human monocytes/macrophages differentiated in the presence of human CSF-1 in the humanized mice exhibit also augmented qualitative, functional properties.

\section{Discussion}

In the present study we documented that replacing the mouse CSF-1 gene with its human counterpart results in efficient human macrophage differentiation in mice that were reconstituted with human hematopoietic stem and progenitor cells. Generating a mouse with a completely reconstituted and functional hematopoietic/ immune system of human origin has been a great challenge in the field. To date, 3 mouse strains (NOD-scid $\gamma c^{-/-}$, [NSG], NOD/Shi-

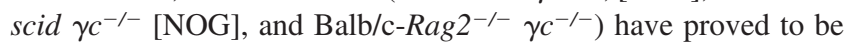
useful candidates for the reconstitution of human hematopoietic system in mice. Despite the advantages conferred by each of these strains, there are several bottlenecks that need to be addressed to optimize the human immune system in mice. The current challenges in using these models include (1) a high degree of variability of the human chimerism within the individual engrafted groups, (2) lack of sustained human hematopoiesis (after 5 months of transplantation), (3) poor or absent development of secondary lymphoid organs (especially peripheral lymph nodes), (4) suboptimal lymphocyte reconstitution (mainly B and T cells), (5) highly reduced myelopoiesis (including granulocytes and macrophages), and (6) almost complete absence of erythrocyte and megakaryocyte differentiation. While efforts have been taken by several investigators to overcome these technical hurdles, the success of using xenogenic models to study human biology is far from being complete.

Our conviction has been that one of the prime reasons for the lack of complete human hematopoiesis in mice might be the deficiency of the microenvironments that support human hematopoiesis in mice. ${ }^{6,24}$ Whereas many of the human cytokines have proven to be cross reactive with murine receptors, unfortunately, many of the murine hematopoietic cytokines are not cross reactive with human cells. We hypothesized that this is one of the major reasons for the poor reconstitution of human myeloid cells in the humanized mice models. In an attempt to overcome this major technical challenge, we reasoned that incorporating the human CSF-1 gene in the Balb/c-Rag2 ${ }^{-/-} \gamma c^{-/-}$mice might improve myeloid reconstitution, particularly the monocyte/macrophage lineage, because CSF-1 is an indispensable cytokine for the differentiation of macrophages. ${ }^{10,11,13,14,25}$ Analysis of the humanized CSF-1 mice indicated efficient differentiation of human monocytes/ macrophages in the BM, spleen and peripheral blood. Moreover, we could detect human macrophages in several different tissues including, lungs and liver, in these mice suggesting that the presence of CSF-1 in humanized mice is sufficient to promote the differentiation of human tissue macrophages. Intriguingly, our functional studies involving the human monocytes/macrophages, isolated from the $C S F 1^{m / m}$ and the $C S F 1^{h / h}$ mice suggest that cells 
A

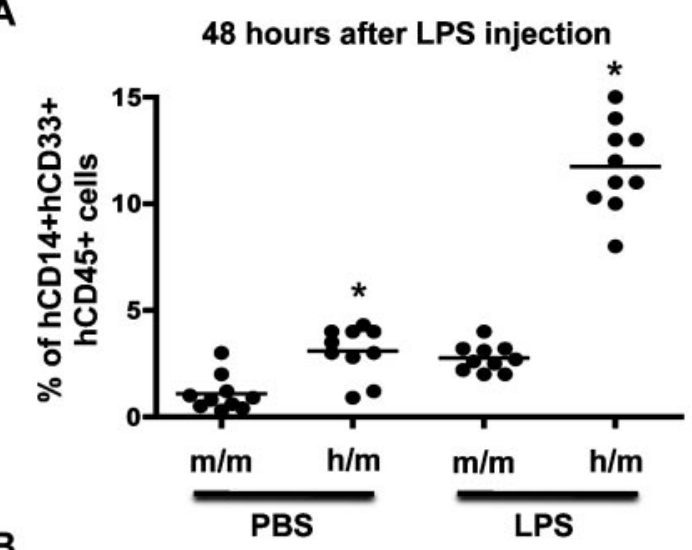

B
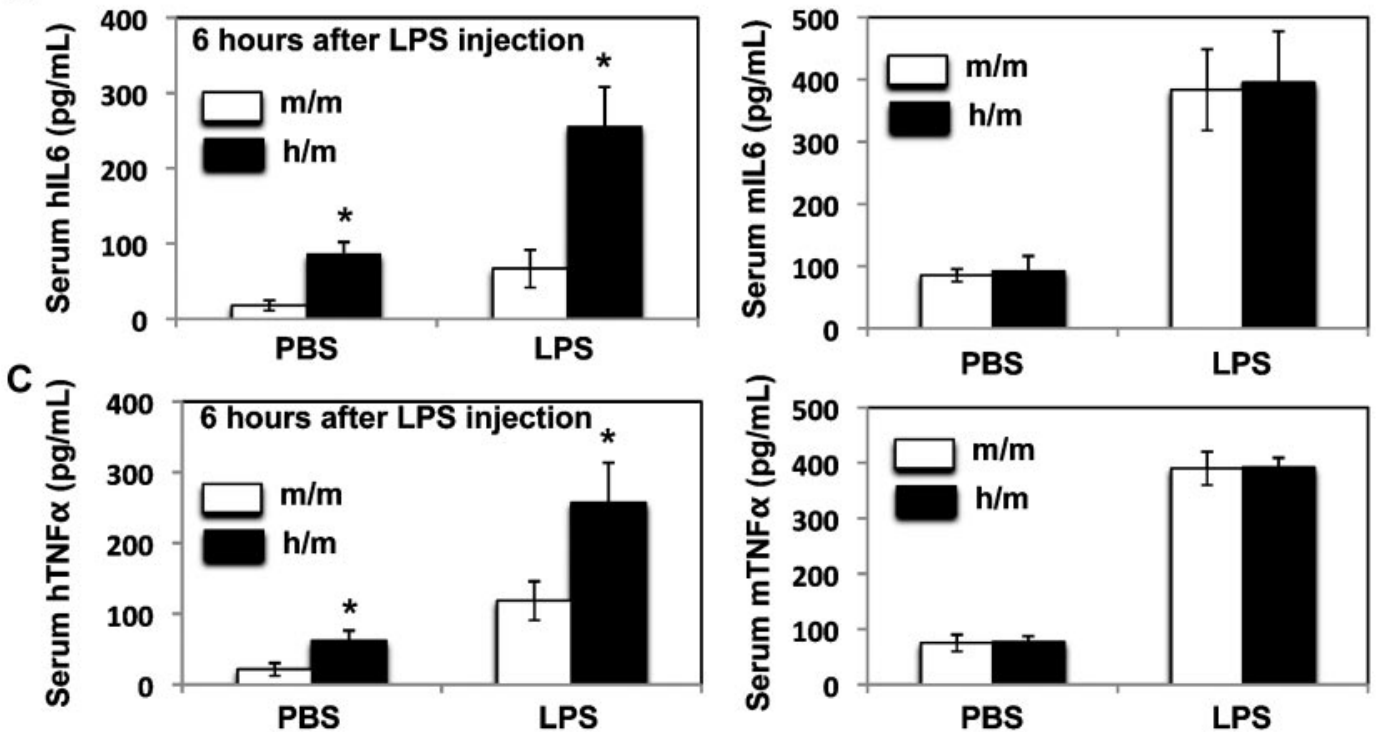

Figure 6. LPS response in vivo. (A) CSF1 $\mathrm{m}^{/ m}$ and $C S F 1^{h / m}$ mice were engrafted with human CD34 ${ }^{+}$cells, and 12 weeks after transplantation LPS was injected intraperitoneally. Forty-eight hours later mice were killed and the frequencies of human $C D 45^{+} \mathrm{CD} 14^{+} \mathrm{CD} 33^{+}$cells in the spleen were determined. PBS-injected mice served as controls. Each symbol represents an individual mouse; horizontal bars indicate the mean values. (B-C) $C S F 1^{m / m}$ and $C S F 1^{h / m}$ mice were engrafted with human CD34 ${ }^{+}$cells, and 12 weeks after transplantation LPS was injected intraperitoneally. Six hours later mice were bled and the serum levels of human (right) and mouse (left) IL-6 and TNF $\alpha$ were quantified through ELISA. PBS-injected mice served as controls. Shown are the mean values of triplicate samples. Error bars indicate \pm SEM.

from the $C S F 1^{h / h}$ mice were better in performing functions such as phagocytosis, migration, activation and cytokine secretion. Based on these findings, it might be inferred that monocytes/ macrophages that differentiate in the presence of human CSF-1 might function better. In line with our observations, it has been shown that CSF-1 is not only responsible for the differentiation of HSC into macrophage lineage cells, but also for the proper functions of macrophages, because constant signaling mediated through CSF-1/CSF-1R is necessary for protein synthesis in macrophages. ${ }^{11}$

In the present study, we adopted the VELOCIGENE technology ${ }^{16}$ to generate a novel line of Balb/c-Rag2 $2^{-/-} \gamma c^{-/-}$mice that express human CSF-1. Accordingly, the mouse CSF-1 coding region was replaced with the human counterpart without disturbing the regulatory elements, such as the promoter, of the mouse csfl gene. This results in a chimeric gene that contains the mouse regulatory elements and the human CSF-1 coding region. Our expression studies indicated that this chimeric gene is expressed faithfully in both a qualitative and quantitative manner. While we were about to complete our studies on the $C S F 1^{h / h}$ mice, a report from the Chen group has documented that transient expression of human CSF-1 in mice results in enhanced reconstitution of human macrophages in the NOD-scid $\gamma c^{-/-}$mice. ${ }^{26}$ In their study, the authors had followed the "hydrodynamic tail vein injection" approach to express human CSF-1 in their mice. While this is an interesting and a rapid approach to express transgenes (such as human cytokines) in mice, it has several technical limitations as follows: (1) only short-term expression of transgenes (usually 2-3 weeks), (2) expression levels of transgene are nonphysiologic, (3) inconsistent levels of transgene expression within experimental groups, and (4) the expression of transgene occurs predominantly in the liver and not in the other tissues. The knockin strategy described in our study overcomes all the above technical limitations.

The role of CSF-1 in the differentiation of mouse macrophages has been well established. Mice that are deficient for either CSF-1 $\left(C s f 1^{o p / o p}\right)$ or its receptor $\left(C s f 1 r^{-/-}\right)$exhibit severe reduction in macrophage and osteoclast frequencies, osteopetrosis, tooth eruption failure, developmental defects in various tissues, including nervous system, male and female fertility, the dermis and synovial membranes. ${ }^{19-22,27-29}$ While these studies have provided very important insights into the roles of CSF-1 in various mouse tissues the significance of CSF-1 in human hematopoiesis remains 
A
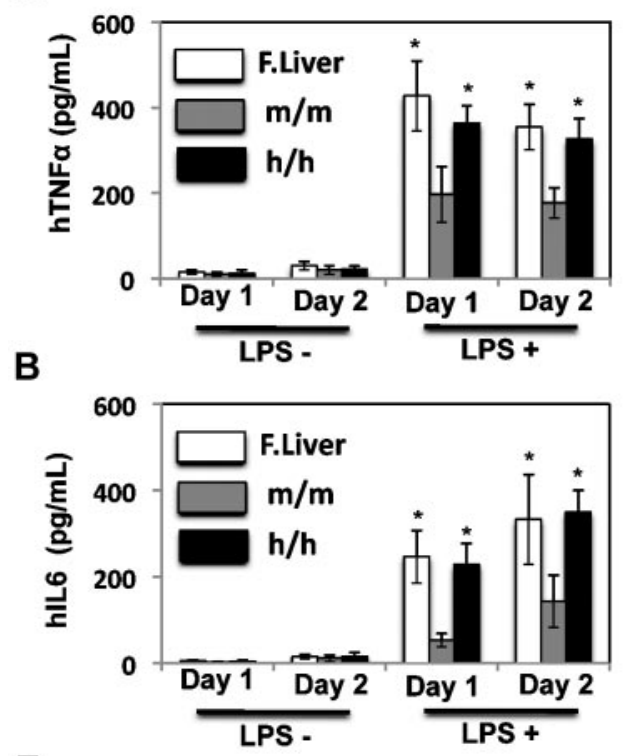

E

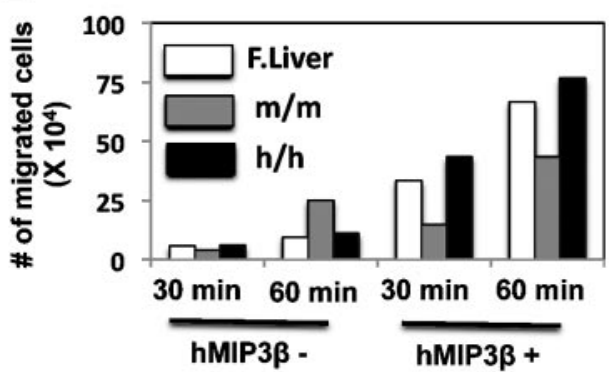

C

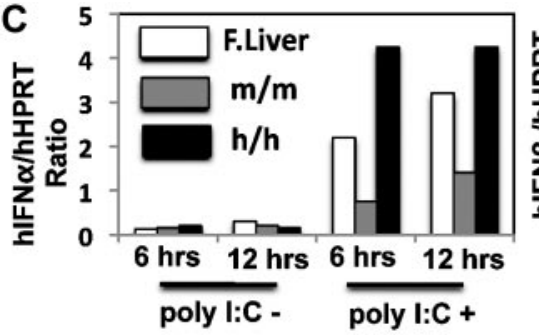

D
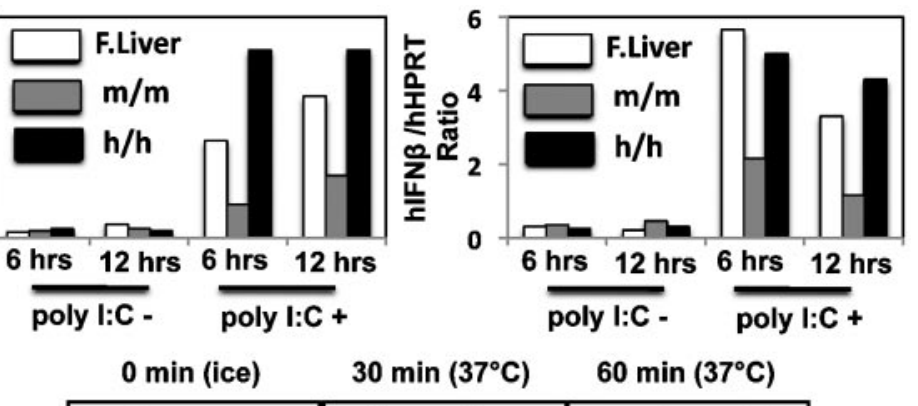

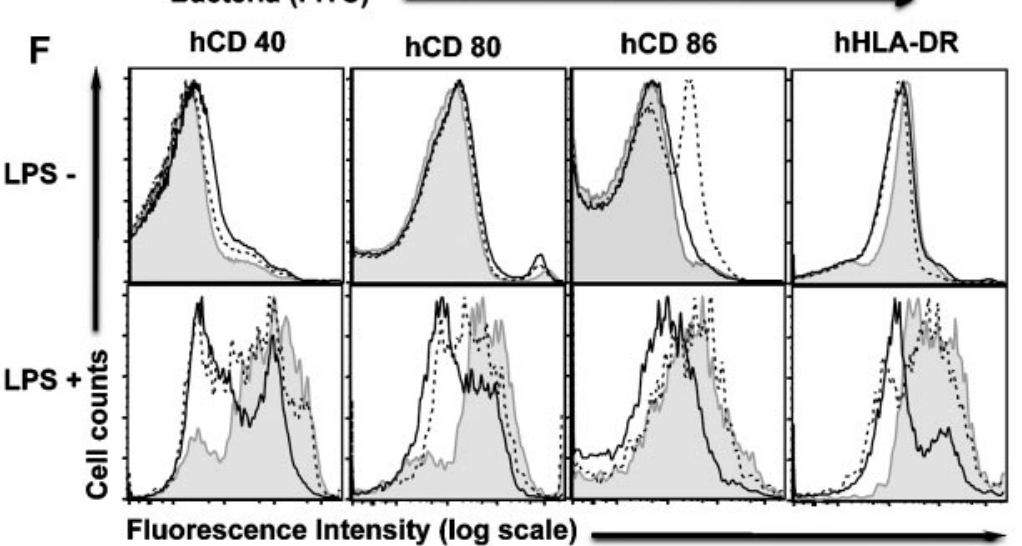

Fluorescence Intensity (log scale)

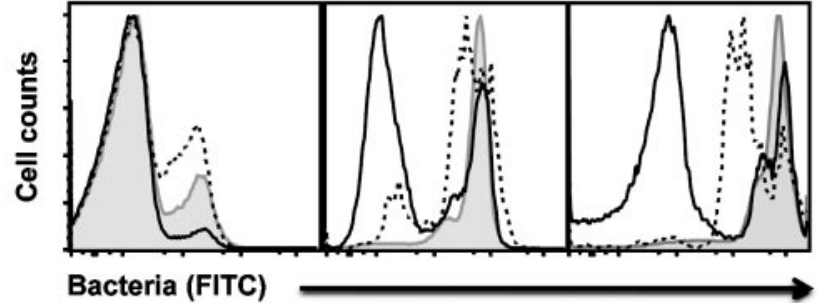

Figure 7. Properties of human monocytes/macrophages isolated from the humanized mice. Human $\mathrm{CD} 45^{+} \mathrm{CD} 14^{+} \mathrm{CD} 33^{+}$cells from the spleens of human $\mathrm{CD} 34^{+}$cells engrafted $C S F 1^{\mathrm{m} / \mathrm{m}}$ and $C S F 1^{\mathrm{h} / \mathrm{h}}$ mice were isolated after 12 weeks of transplantation. Human $\mathrm{CD} 45^{+} \mathrm{CD} 14^{+} \mathrm{CD} 33^{+}$cells obtained from the fetal liver served as controls. Cells were stimulated in vitro with LPS either for 24 or 48 hours, cell culture supernatants were collected and the levels of human TNF $\alpha$ (A) and IL-6 (B) were quantified through ELISA. Shown are the mean values of triplicate samples. Error bars indicate \pm SEM. (C) Human $\mathrm{CD}_{4} 5^{+} \mathrm{CD} 14^{+} \mathrm{CD} 33^{+}$cells were stimulated poly I:C for either 6 or 12 hours and the IFN $\alpha$ (left) and IFN $\beta$ (right) mRNA levels were quantified through Real Time PCR. Shown are the mean values of duplicate samples. (D) Human CD45 ${ }^{+}$CD14 ${ }^{+}$CD $33^{+}$ cells were isolated from the humanized mice and incubated with FITC-labeled bacteria at $37^{\circ} \mathrm{C}$ either for 30 or 60 minutes and measured by flow cytometry. Cells incubated with FITC-labeled bacteria on ice served as controls. Open histograms represent cells obtained from the CSF1 $\mathrm{m} / \mathrm{m}$ mice, dotted histograms represent cells obtained from the $C S F 1^{h / h}$ mice and filled histograms represent cells obtained from human fetal liver. (E) Human CD $45^{+} \mathrm{CD} 14^{+} \mathrm{CD} 33^{+}$cells isolated from $C S F 1^{m / m}$ mice, $C S F 1^{h / h}$ mice and human fetal liver were kept in the upper wells and the medium containing MIP3 $\beta$ was added in the lower wells. Cells were incubated for either 30 or 60 minutes and the number of cells migrated from the upper wells to the lower wells was calculated and plotted. Shown are the mean values of duplicate samples. (F) Human CD45 ${ }^{+} \mathrm{CD} 14^{+} \mathrm{CD} 33^{+}$cells isolated from $C S F 1^{\mathrm{m} / \mathrm{m}}$ mice, $C S F 1^{\mathrm{h} / \mathrm{h}}$ mice and human fetal liver were cultured either in the presence or in the absence of LPS. After 24 hours of stimulation, cells were stained with indicated surface markers and measured by flow cytometry. Open histograms represent cells obtained from the CSF ${ }^{\mathrm{m} / \mathrm{m}}$ mice, dotted histograms represent cells obtained from the $C S F 1^{h / h}$ mice and filled histograms represent cells obtained from human fetal liver.

largely unknown. This is because of obvious ethical and technical difficulties in using human subjects for studying human biology. In this regard, our mice that are engineered to express human cytokines, will serve as valuable tools, because this approach not only improves the reconstitution of human hematopoietic cells in the humanized mice, but also enables improved understanding of the physiology and functions of cytokines in human hematopoiesis. Thus, the current approach involving the $C S F 1^{h / h}$ mice model serves as a "gain of function" study to highlight the importance of CSF-1 in the development and functions of human macrophages. In essence, these findings provide further proof of principle that genetic manipulation of the existing humanized mouse models will significantly improve the overall engraftment of human tissues and will prove to be valuable tools in understanding the pathophysiology and in the treatment of several human disorders and diseases.

\section{Acknowledgments}

The authors thank J. Alderman for the organizational support, A. M. Franco for the isolation of $\mathrm{CD}_{3} 4^{+}$cells, P. Ranney for the help with mouse breeding, R. Webber for mouse engraftment, P. Ziegler for intra-liver injection training, and colleagues from Regeneron's Velocigene for their technical contributions. They also thank the Albert Einstein College of Medicine and Advanced Biosciences Resources for the help in collecting human liver samples and F. Manzo for the help with manuscript submission.

This work is supported by grants from the Bill and Melinda Gates Foundation through the Grand Challenges in Global Health Initiative (C.R., A.R., E.E.E., M.G.M., and R.A.F.) and 
the Juvenile Diabetes Research Foundation. R.A.F. is an investigator of the Howard Hughes Medical Institute.

\section{Authorship}

Contribution: C.R. designed and performed all the experiments, analyzed and interpreted data, and wrote the manuscript; W.T.P., J.R., A.J.M., D.M.V., and G.D.Y. generated the CSF-1 KI mice; A.R. provided help with maintaining the animal colony; E.E.E. gave conceptual advice and corrected the manuscript; and M.G.M. and R.A.F. conceived the study, supervised the project, and corrected the manuscript.

Conflict-of-interest disclosure: W.T.P., J.R., A.J.M., D.M.V., and G.D.Y. are employees of Regeneron Pharmaceuticals. The remaining authors declare no competing financial interests.

The current affiliation for C.R. is Department of Genetics and Development, Columbia University, New York, NY.

Correspondence: Prof Richard A. Flavell, Yale University School of Medicine, 300 Cedar St, TAC S-569, PO Box 208011, New Haven, CT 06520-801L; e-mail: richard.flavell@yale.edu; and Prof Markus G. Manz, University Hospital Zurich, Rämistrasse 100, CH-8091 Zurich, Switzerland; e-mail: markus.manz@usz.ch.

\section{References}

1. Mestas J, Hughes CC. Of mice and not men: differences between mouse and human immunology. J Immunol. 2004;172(5):2731-2738.

2. Shultz LD, Ishikawa F, Greiner DL. Humanized mice in translational biomedical research. Nat Rev Immunol. 2007;7(2):118-130.

3. Macchiarini F, Manz MG, Palucka AK, Shultz LD. Humanized mice: are we there yet? J Exp Med. 2005;202(10):1307-1311.

4. Hiramatsu H, Nishikomori R, Heike T, et al. Complete reconstitution of human lymphocytes from cord blood CD34 + cells using the NOD/SCID/ gammacnull mice model. Blood. 2003;102(3): 873-880.

5. Ishikawa F, Yasukawa M, Lyons B, et al. Development of functional human blood and immune systems in NOD/SCID/IL2 receptor \{gamma\} chain(null) mice. Blood. 2005;106(5):1565-1573.

6. Manz MG. Human-hemato-lymphoid-system mice: opportunities and challenges. Immunity. 2007;26(5):537-541.

7. Shultz LD, Lyons BL, Burzenski LM, et al. Human lymphoid and myeloid cell development in NOD/ LtSz-scid IL2R gamma null mice engrafted with mobilized human hemopoietic stem cells. J Immunol. 2005;174(10):6477-6489.

8. Traggiai E, Chicha L, Mazzucchelli L, et al. Development of a human adaptive immune system in cord blood cell-transplanted mice. Science. 2004; 304(5667):104-107.

9. Yahata T, Ando K, Nakamura Y, et al. Functional human $T$ lymphocyte development from cord blood CD34 + cells in nonobese diabetic/Shi-scid, IL-2 receptor gamma null mice. J Immunol. 2002; 169(1):204-209.

10. Sherr CJ, Rettenmier CW, Roussel MF. Macrophage colony-stimulating factor, CSF-1, and its proto-oncogene-encoded receptor. Cold Spring Harb Symp Quant Biol. 1988;53 Pt1:521-530.
11. Pixley FJ, Stanley ER. CSF-1 regulation of the wandering macrophage: complexity in action. Trends Cell Biol. 2004;14(11):628-638.

12. Socolovsky M, Constantinescu SN, Bergelson S, Sirotkin A, Lodish HF. Cytokines in hematopoiesis: specificity and redundancy in receptor function. Adv Protein Chem. 1998;52:141-198.

13. Stanley ER, Berg KL, Einstein DB, et al. Biology and action of colony-stimulating factor-1. Mol Reprod Dev. 1997;46(1):4-10.

14. Rohrschneider LR, Bourette RP, Lioubin MN, Algate PA, Myles GM, Carlberg K. Growth and differentiation signals regulated by the M-CSF receptor. Mol Reprod Dev. 1997;46(1):96-103.

15. Yeung YG, Stanley ER. Proteomic approaches to the analysis of early events in colony-stimulating factor-1 signal transduction. Mol Cell Proteomics. 2003;2(11):1143-1155.

16. Valenzuela DM, Murphy AJ, Frendewey D, et al. High-throughput engineering of the mouse genome coupled with high-resolution expression analysis. Nat Biotechnol. 2003;21(6):652-659.

17. Frendewey D, Chernomorsky R, Esau L, et al. The loss-of-allele assay for ES cell screening and mouse genotyping. Methods Enzymol. 2010;476: 295-307.

18. Poueymirou WT, Auerbach W, Frendewey D, et al. FO generation mice fully derived from genetargeted embryonic stem cells allowing immediate phenotypic analyses. Nat Biotechnol. 2007; 25(1):91-99.

19. Dai XM, Ryan GR, Hapel AJ, et al. Targeted disruption of the mouse colony-stimulating factor 1 receptor gene results in osteopetrosis, mononuclear phagocyte deficiency, increased primitive progenitor cell frequencies, and reproductive defects. Blood. 2002;99(1):111-120.

20. Felix R, Cecchini MG, Fleisch H. Macrophage colony stimulating factor restores in vivo bone resorption in the op/op osteopetrotic mouse. Endocrinology. 1990;127(5):2592-2594.

21. Wiktor-Jedrzejczak W, Bartocci A, Ferrante AW Jr, et al. Total absence of colony-stimulating factor 1 in the macrophage-deficient osteopetrotic (op/op) mouse. Proc Natl Acad Sci U S A. 1990;87(12) 4828-4832.

22. Yoshida H, Hayashi S, Kunisada T, et al. The murine mutation osteopetrosis is in the coding region of the macrophage colony stimulating factor gene. Nature. 1990;345(6274):442-444

23. Sieff CA. Hematopoietic growth factors. J Clin Invest. 1987;79(6):1549-1557.

24. Legrand N, Ploss A, Balling R, et al. Humanized mice for modeling human infectious disease: challenges, progress, and outlook. Cell Host Microbe. 2009;6(1):5-9.

25. Hamilton JA. CSF-1 signal transduction. J Leukoc Biol. 1997;62(2):145-155.

26. Chen Q, Khoury M, Chen J. Expression of human cytokines dramatically improves reconstitution of specific human-blood lineage cells in humanized mice. Proc Natl Acad Sci U S A. 2009;106(51): 21783-21788.

27. Cecchini MG, Dominguez MG, Mocci S, et al. Role of colony stimulating factor- 1 in the establishment and regulation of tissue macrophages during postnatal development of the mouse. Development. 1994;120(6):1357-1372.

28. Cohen PE, Nishimura K, Zhu L, Pollard JW. Macrophages: important accessory cells for reproductive function. J Leukoc Biol. 1999;66(5):765-772.

29. Michaelson MD, Bieri PL, Mehler MF, et al. CSF-1 deficiency in mice results in abnormal brain development. Development. 1996;122(9):26612672 